\title{
An Analysis of Pharmacy Students' Social Networking Service Activities and Perceptions Regarding E-Professionalism under the Newly Implemented 6-year Pharmacy Educational System in South Korea
}

\author{
Young-Mo Yang ${ }^{1}$, Eun Jeong ${ }^{2}$, Nam Kyung Je ${ }^{3}$, Jun-Pil Jee ${ }^{1}$, Jin Cheol Yoo' and Eun Joo Choi ${ }^{*}$ \\ ${ }^{1}$ Department of Pharmacy, College of Pharmacy, Chosun University, Gwangju, South Korea. \\ ${ }^{2}$ Department of Food and Nutrition, Chosun University, Gwangju, South Korea. \\ ${ }^{3}$ Department of Pharmacy, College of Pharmacy, Pusan National University, Busan, South Korea.
}

\begin{abstract}
Background: In the transitional period of Korean pharmacy educational system from 4-year to 6-year, it is crucial to provide pharmacy students with a proper training in professionalism in order for them to succeed as future medication experts appropriately prepared for their attitudes and behaviors online as well as off-line. Consequently, it is necessary to comprehend current social networking service (SNS) activities and perceptions of pharmacy students regarding e-professionalism. The aims of this study were to examine the use patterns of SNSs among pharmacy students and assess their perceptions regarding e-professionalism on popular SNSs under the newly implemented 6-year pharmacy educational system in South Korea. Methods: Survey instruments were administered to the first-, second-, and third-year pharmacy students $(n=223)$ of Chosun University in Korea between September and October 2014. Results: Of 210 (94.2\%) students who responded to the survey, $72.4 \%$ had 2 or 3 SNS profiles. More than $90 \%$ of students felt that pharmacy students should be accountable for their unethical or unprofessional behaviors presented on SNSs. Conclusion: Many Korean pharmacy students use SNSs. However, the term "e-professionalism" is relatively new and unfamiliar in Korea. Faculty members and administrators of pharmacy schools in Korea should introduce new issues related with "e-professionalism" to pharmacy students and make them familiar with it before starting to seek pharmacy jobs.
\end{abstract}

Key words: Social networking service, Pharmacy students, e-professionalism, Social media, Perception.

Key Messages: More than $92 \%$ of participants responded that pharmacy students should have responsibility for their unethical or unprofessional behaviors displayed on social networks, and approximately $56 \%$ of participants answered that pharmacy students should have higher standards about their images presented on social networks.

\section{INTRODUCTION}

The Social networking service (SNS) is a platform which allows people to build online social relations with known or unknown people who share useful information (such as interests or activities). ${ }^{1,2}$ Many widespread SNSs such as Facebook, Twitter, Kakaotalk and Naverband enable their users to join and create social groups for those who have similar interests and to interact with them. ${ }^{1}$ The SNSs are popular even in older generations as well as in younger genera- tions. ${ }^{3}$ In particular, Kakaotalk, introduced to the SNS market in March 2010, is the No. 1 SNS in Korea, and 70 million people including over $90 \%$ of Korean's smartphone users registered Kakaotalk worldwide in December $2012 .^{4}$

Partially owing to the popularity of SNSs, the pattern of how individuals communicate has been altered. In other words, the communication paradigm between individ-
Submission Date : 27-07-2015 Revision Date :22-08-2015 Accepted Date :20-10-2015

DOI: 10.5530/ijper.50.1.9 Correspondence Address Eun Joo Choi, PharmD, MS DepartmentofPharmacy,

College of Pharmacy, Chosun University, 309 Pilmun-daero, Dong-gu, Gwangju61452, South Korea.

Phoneno:+82-62-230-6382 E-mail:ejchoi@chosun.ac.kr

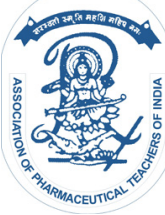

www.ijper.org 
uals has been continuously transformed from face-toface or telephone patterns to a web-based SNS pattern. ${ }^{3}$ SNSs have beneficial aspects in building and maintaining long-standing social relations with friends or colleagues; however, SNSs can not only expose people to dangers in their privacy and safety but also raise serious professional issues. ${ }^{5,6}$ Information presented on the SNSs (such as comments, opinions, and photographs) could be used to determine healthcare students' professionalism and could also harm themselves, colleagues, and even patients because private information may be potentially exposed to unknown people. ${ }^{6,7}$ Thus, the concept of e-professionalism has arisen, and it is defined as the attitudes and behaviors reflecting the concept of traditional professionalism on SNSs. ${ }^{6,8}$ The issues with regard to e-professionalism may be persistently significant as healthcare providers and students keep communicating via SNSs. ${ }^{9}$

In other countries, some studies regarding e-professionalism have been conducted in order to understand how healthcare students display themselves on SNSs. Student doctors in New Zealand presented sexual orientation, offensive language, unprofessional photographs (e.g., pictures with patients, excessive alcohol consumption), and involvement in unprofessional groups (e.g., "F*** medicine - I want to be a ninja," "Perverts united") on their Facebook pages. ${ }^{10,11}$ A nursing student at the University of Louisville in the United States was expelled for violating the honor code by posting unprofessional comments on an SNS about patients whom she had met on her clinical rotations. ${ }^{3,11}$ Approximately $45 \%$ of pharmacy students at Queen's University Belfast in the United Kingdom indicated that they had posted content that they did not want a prospective employer or university administrator to view. ${ }^{11,12} \mathrm{~A}$ study analyzing the first-year pharmacy students in the United States reported that approximately $65 \%$ of these students indicated their online images on Facebook accurately showed future images as healthcare professionals. ${ }^{6}$

Korean pharmacy educational system was reformed from 4- to 6-year $(2+4)$ program in 2009, and it is necessary for students to compete at least 2 years of an undergraduate program before entering pharmacy schools. ${ }^{13}$ In this transitional period, it is crucial to provide pharmacy students with a proper training in professionalism in order for them to succeed as future medication experts appropriately prepared for their attitudes and behaviors online as well as off-line. Consequently, it is necessary to comprehend current SNS activities and perceptions of pharmacy students regarding e-professionalism. Although several studies regarding professionalism of healthcare students on SNSs were conducted in foreign countries ${ }^{3,5-7,7-12}$, these kinds of studies with pharmacy students have been rarely implemented in Korea.

The objectives of this study were to (1) examine the use patterns of SNSs among pharmacy students and (2) assess students' perceptions regarding e-professionalism on popular SNSs under the newly implemented 6-year pharmacy educational system in South Korea.

\section{MATERIALS AND METHODS}

A survey instrument was developed after reviewing the relevant literature. ${ }^{6,11}$ The pilot test for the survey questions was conducted with 12 pharmacy students, and minor revisions were made based on the results from the pilot test. The survey instrument consisted of 20 questions regarding demographic data, SNS activities, and perceptions of e-professionalism. Most of the survey questions were closed with pre-formulated answer choices. A brief explanation on the objectives of the survey was provided on the questionnaire. The institutional review board of Chosun University reviewed and approved the proposed study.

In September and October 2014, the first-, second-, and third-year pharmacy students $(n=223)$ at Chosun University were invited to participate in the study. The fourth-year pharmacy students were excluded from the study because they were on their clinical rotations during the study period. Self-reported questionnaires were distributed to the study population after thoroughly explaining the purposes of this study during the classes. However, the students had not received any instruction about professionalism and ethics associated with SNSs prior to participation in the survey. The completion of the survey was means for consent. The survey was conducted anonymously, and it took approximately 5-10 minutes to complete.

Responses were coded and transferred into SPSS for Windows, version 20.0 (SPSS Inc., Chicago). Continuous variables were presented as mean $\pm \mathrm{SD}$, and categorical variables as frequency (n) and percentage (\%). The T-test and chi-square test were used to compare the differences in means and proportions between male and female, respectively. The a-priori level of $p$ value was set at $p<0.05$ and missing data were not estimated or included in the analysis.

\section{RESULTS}

The response rate of the survey was $94.2 \%$ with the participation of 210 students. Approximately $52 \%$ of 
the participants were male students $(110 / 210)$. The mean age of total participants was $25.4 \pm 3.3$ years. The majority of participants $(60.4 \%, 125 / 210)$ completed the second year in other colleges before entering a pharmacy school. Table 1 represents other demographic characteristics of participants in more detail.

\section{Trends in Social Network Activities of Participants}

All participants $(100 \%)$ had at least 1 social network account at the time of the survey, and the majority of participants $(72.4 \%, 152 / 210)$ possessed 2 or 3 social network accounts. Kakaotalk was the most popular social network site which participants $(95.2 \%, 200 / 210)$ used followed by Facebook $(70.5 \%, 148 / 210)$ and Naverland $(53.3 \%, 112 / 210)$. The majority of participants $(67.6 \%, 140 / 207)$ logged in to their accounts at least 5 times per day with more females $(73.7 \%, 73 / 99)$ than males (62.0\%, 67/108). Approximately 93\% (195/210) of participants used real names on social networks, and females were less likely to provide real names on social networks than males $(p=0.002)$. About $81 \%$ of participants used privacy settings on social networks. Participants spent an average of $8.7 \pm 8.6$ minutes on social networks per visit, and females (9.1 \pm 9.1 minutes) tended to spend more time on social networks per visit than males ( $8.4 \pm 8.2$ minutes); however, there was no significant difference between two groups $(p=0.583)$. Table 2 represents other findings of social network activities of participants in more detail.

\section{Perceptions of Participants on E-professionalism Related with Social Networks}

The majority of participants $(92.4 \%, 194 / 210)$ thought that pharmacy students should be responsible for their unethical or unprofessional behaviors displayed on social networks. Approximately $79 \%$ of participants $(166 / 209)$ thought that information on social networks affects others' opinions of them. About $56 \%$ of participants $(118 / 209)$ indicated that pharmacy students should have higher standards regarding their images presented on social networks. About 59\% of participants $(125 / 210)$ indicated that future employers should consider an applicant's profile information when making a hiring decision. Over half of participants $(55.0 \%$, $115 / 209)$ wanted their faculty members to use social networks to keep a close relationship with them. The majority of participants $(71.6 \%, 149 / 208)$ indicated that a lecture or workshop regarding online professional etiquette would be helpful to keep e-professionalism online in the future. A small number of participants had provided information on social networks that they did not want faculty members $(15.2 \%, 32 / 210)$ or future employers $(12.1 \%, 25 / 207)$ to view. There were no significant differences in opinions on e-professionalism between males and females. Table 3 shows other results regarding opinions of participants on e-professionalism related with social networks in more detail.

\section{DISCUSSION}

This study investigated the patterns of using SNSs among pharmacy students and evaluated their perceptions with regard to e-professionalism on popular SNSs under the newly implemented 6-year pharmacy educational system in South Korea. To our knowledge, this study is the first to observe Korean pharmacy students' activities and perceptions regarding e-professionalism on SNSs. Most students (95.2\%) who participated in this study had Kakaotalk profiles. Approximately $70 \%$ of students had Facebook profiles, but the percentage of Korean pharmacy students with Facebook profiles is lower than those reported for pharmacy students in the United States and the United Kingdom. ${ }^{6,12}$ This may be because more than $90 \%$ of Korean's smartphone users have Kakaotalk profiles and this is overwhelmingly the No. 1 SNS used by Korean people. ${ }^{4}$

The majority of students tended to visit SNSs more than 5 times daily, and the average time spent on an SNS per visit was 8.7 minutes. Comparing with this result, most pharmacy students $(83.8 \%)$ in the United Kingdom responded that they invested less than 2 hours to use SNSs although a small percentage of the students $(2.3 \%)$ spent more than 3 hours per day on SNSs. ${ }^{12}$ These results may suggest that using SNSs plays an important role in keeping relations between participants in daily lives.

One of the interesting findings from this study is that $40.5 \%$ of Korean pharmacy students indicated that a pharmacy employer should not consider a prospective employee's SNS profile in making a hiring decision. This result is similar to that from the study conducted with graduating pharmacy students in the United States. They also felt that SNS profiles should not be considered $(45 \%) .{ }^{10}$ In contrast, more first-year pharmacy students $(57.4 \%)$ believed that it is unfair to refer to their SNS profiles in making a hiring decision. ${ }^{6}$ The different results between the two studies may stem from demographic and geographic differences. The participants of this study consisted of the first-, second-, and thirdyear pharmacy students in Korea whereas only first-year pharmacy students in the United States participated in the other study. In addition, the time when each study was conducted led to differences in responses. In general, it is likely that using SNSs is more popular among 


\begin{tabular}{|c|c|c|c|c|c|}
\hline Characteristic & & \multicolumn{4}{|c|}{ N (\%) } \\
\hline Gender & Male & \multicolumn{4}{|c|}{$110 / 210(52.4)$} \\
\hline & Female & \multicolumn{4}{|c|}{$100 / 210(47.6)$} \\
\hline \multirow[t]{3}{*}{ Average age ( $\pm S D$ ) (year) } & & \multicolumn{4}{|c|}{$25.4 \pm 3.3$} \\
\hline & & \multicolumn{4}{|c|}{$\mathbf{N}(\%)$} \\
\hline & & Total & Male & Female & p-value* \\
\hline \multirow{3}{*}{$\begin{array}{l}\text { Current grade in a } \\
\text { pharmacy school }\end{array}$} & $1^{\text {st }}$ year & $72 / 210(34.3)$ & $36 / 110(32.7)$ & $36 / 100(36.0)$ & \multirow{3}{*}{0.737} \\
\hline & $2^{\text {nd }}$ year & $62 / 210(29.5)$ & $35 / 110(31.8)$ & $27 / 100(27.0)$ & \\
\hline & $3^{\text {rd }}$ year & $76 / 210(36.2)$ & $39 / 110(35.5)$ & $37 / 100(37.0)$ & \\
\hline \multirow{4}{*}{$\begin{array}{l}\text { Academic background } \\
\text { before a pharmacy school }\end{array}$} & $2^{\text {nd }}$ year completion & $125 / 210(60.4)$ & $68 / 110(63.0)$ & $57 / 100(57.6)$ & \multirow{4}{*}{0.023} \\
\hline & $3^{\text {rd }}$ year completion & $29 / 210(14.0)$ & $20 / 110(18.5)$ & $9 / 100(9.1)$ & \\
\hline & BS & $47 / 210(22.7)$ & $17 / 110(15.7)$ & $30 / 100(30.3)$ & \\
\hline & MS or higher & $6 / 210(2.9)$ & $3 / 110(2.8)$ & $3 / 100(3.0)$ & \\
\hline
\end{tabular}

Abbreviations: $\mathrm{BS}$ = bachelor of science; $\mathrm{MS}$ = master of science

* derived from chi-square test

\begin{tabular}{|c|c|c|c|c|c|}
\hline \multirow{2}{*}{ Variable } & & \multicolumn{4}{|c|}{ N (\%) } \\
\hline & & Total & Male & Female & p-value \\
\hline \multirow{4}{*}{$\begin{array}{l}\text { Number of social network } \\
\text { accounts }\end{array}$} & 1 & $40 / 210(19.0)$ & $24 / 110(21.8)$ & $16 / 100(16.0)$ & \multirow{4}{*}{0.711} \\
\hline & 2 & $81 / 210(38.6)$ & $41 / 110(37.3)$ & $40 / 100(40.0)$ & \\
\hline & 3 & $71 / 210(33.8)$ & $35 / 110(31.8)$ & $36 / 100(36.0)$ & \\
\hline & 4 & $18 / 210(8.6)$ & $10 / 110(9.1)$ & $8 / 100(8.0)$ & \\
\hline \multirow{4}{*}{ Social networks in use ${ }^{a}$} & Kakaotalk & $200 / 210(95.2)$ & $104 / 110(94.5)$ & $96 / 100(96.0)$ & 0.621 \\
\hline & Facebook & $148 / 210(70.5)$ & $76 / 110(69.1)$ & $72 / 100(72.0)$ & 0.644 \\
\hline & Naverland & $112 / 210(53.3)$ & $58 / 110(52.7)$ & $54 / 100(54.0)$ & 0.854 \\
\hline & Twitter & $27 / 210(12.9)$ & $13 / 110(11.8)$ & $14 / 100(14.0)$ & 0.637 \\
\hline \multirow{5}{*}{$\begin{array}{c}\text { Frequency of social network } \\
\text { use per day }\end{array}$} & 1 & $36 / 207(17.4)$ & $25 / 108(23.1)$ & $11 / 99(11.1)$ & \multirow{5}{*}{0.137} \\
\hline & 2 & $11 / 207(5.3)$ & 4/108 (3.7) & $7 / 99(7.1)$ & \\
\hline & 3 & $13 / 207(6.3)$ & $8 / 108(7.4)$ & $5 / 99(5.1)$ & \\
\hline & 4 & $7 / 207(3.4)$ & 4/108 (3.7) & $3 / 99(3.0)$ & \\
\hline & $\geq 5$ & $140 / 207(67.6)$ & $67 / 108(62.0)$ & 73/99 (73.7) & \\
\hline $\begin{array}{c}\text { Real names in use on social } \\
\text { networks }\end{array}$ & & $195 / 210(92.9)$ & $108 / 110(98.2)$ & $87 / 100(87.0)$ & 0.002 \\
\hline $\begin{array}{l}\text { Privacy settings in use on } \\
\text { social networks }\end{array}$ & & $169 / 210(80.5)$ & $90 / 110(81.8)$ & $79 / 100(79.0)$ & 0.607 \\
\hline $\begin{array}{l}\text { Average spending time } \\
\text { on social networks per visit } \\
( \pm S D) \text { (minute) }\end{array}$ & & $8.7 \pm 8.6$ & $8.4 \pm 8.2$ & $9.1 \pm 9.1$ & 0.583 \\
\hline
\end{tabular}

${ }^{a}$ Multiple answers allowed

* derived from chi-square test

students now than in the past; therefore, they may become more familiar with the idea that future employers often use prospective employees' SNS profiles to obtain information not presented on their resumes.

Another interesting finding of the present study is associated with students' images portrayed on SNSs. About $40 \%$ of students showed that their images presented online through SNSs accurately reflected who they were as a person, but less than one-fifth of students indicated that their SNS profiles portrayed images as a future healthcare provider. This difference could reveal that most students in this study felt their SNS profiles should not be considered to judge their character and professionalism since these profiles involve information that is privately shared with close people. Otherwise, they had not previously thought about e-professionalism; therefore, they did not keep their professional images online. In addition, when comparing the studies, differences among responses also exist. The majority (84.8\%) of the first-year pharmacy students in the United States showed that their images presented through an SNS accurately reflected who they were as a person. ${ }^{6}$ Approximately 65\% indicated that their online profiles reflected who they would be as a future healthcare provider. ${ }^{6}$ The different results between two studies may result from a different degree of interest in e-professionalism between two countries. Unlike the study conducted in the United States, all SNSs available in 


\begin{tabular}{|c|c|c|c|c|}
\hline \multirow{2}{*}{ Questionnaire Item } & \multicolumn{4}{|c|}{ Yes, N (\%) } \\
\hline & Total & Male & Female & p-value \\
\hline $\begin{array}{c}\text { Do you participate in social networking activities associated with } \\
\text { pharmacy or a pharmacy school? }\end{array}$ & $\begin{array}{c}83 / 209 \\
(39.7)\end{array}$ & $\begin{array}{c}50 / 109 \\
(45.9)\end{array}$ & $\begin{array}{c}33 / 100 \\
(33.0)\end{array}$ & 0.057 \\
\hline $\begin{array}{l}\text { Do you think that your images on social networks properly reflect who } \\
\text { you are? }\end{array}$ & $\begin{array}{c}84 / 208 \\
(40.4)\end{array}$ & $\begin{array}{c}47 / 108 \\
(43.5)\end{array}$ & $\begin{array}{c}37 / 100 \\
(37.0)\end{array}$ & 0.338 \\
\hline $\begin{array}{l}\text { Do you think that your images on social networks properly reflect } \\
\text { those of a future professional? }\end{array}$ & $\begin{array}{c}40 / 209 \\
(19.1)\end{array}$ & $\begin{array}{c}26 / 109 \\
(23.9)\end{array}$ & $\begin{array}{l}14 / 100 \\
(14.0)\end{array}$ & 0.070 \\
\hline $\begin{array}{c}\text { Do you think that the students who will work as professionals should } \\
\text { keep higher standards about their images than others? }\end{array}$ & $\begin{array}{c}118 / 209 \\
(56.5)\end{array}$ & $\begin{array}{c}63 / 109 \\
(57.8)\end{array}$ & $\begin{array}{c}55 / 100 \\
(55.0)\end{array}$ & 0.684 \\
\hline $\begin{array}{l}\text { Do you think that you as a pharmacy student should be responsible for } \\
\text { your unethical or unprofessional behavior found through postings on } \\
\text { social networks? }\end{array}$ & $\begin{array}{c}194 / 210 \\
(92.4)\end{array}$ & $\begin{array}{c}102 / 110 \\
(92.7)\end{array}$ & $\begin{array}{c}92 / 100 \\
(92.0)\end{array}$ & 0.843 \\
\hline $\begin{array}{l}\text { Do you think that information (such as photos, groups, postings, } \\
\text { and comments) posted on social networks has an effect on people's } \\
\text { opinion of you as a professional healthcare provider? }\end{array}$ & $\begin{array}{c}166 / 209 \\
(79.4)\end{array}$ & $\begin{array}{c}84 / 109 \\
(77.1)\end{array}$ & $\begin{array}{c}82 / 100 \\
(82.0)\end{array}$ & 0.378 \\
\hline $\begin{array}{l}\text { Have you posted information (such as a photo, message, join the } \\
\text { group, etc.) on social networks that you do not want your faculty } \\
\text { member to see? }\end{array}$ & $\begin{array}{c}32 / 210 \\
(15.2)\end{array}$ & $\begin{array}{l}16 / 110 \\
(14.5)\end{array}$ & $\begin{array}{l}16 / 100 \\
(16.0)\end{array}$ & 0.770 \\
\hline $\begin{array}{c}\text { Have you posted information (such as a photo, message, join the } \\
\text { group, etc.) on social networks that you do not want your future } \\
\text { employer to see? }\end{array}$ & $\begin{array}{r}25 / 207 \\
(12.1)\end{array}$ & $\begin{array}{c}15 / 108 \\
(13.9)\end{array}$ & $\begin{array}{l}10 / 99 \\
(10.1)\end{array}$ & 0.403 \\
\hline $\begin{array}{l}\text { If a pharmacy employer decides to review a prospective employee's } \\
\text { social network account, do you think that the profile information } \\
\text { should be considered when making a hiring decision? }\end{array}$ & $\begin{array}{c}125 / 210 \\
(59.5)\end{array}$ & $\begin{array}{c}67 / 110 \\
(60.9)\end{array}$ & $\begin{array}{c}58 / 100 \\
(58.0)\end{array}$ & 0.668 \\
\hline $\begin{array}{l}\text { Do you want your faculty member to utilize social networks in order to } \\
\text { keep a close relationship with you? }\end{array}$ & $\begin{array}{c}115 / 209 \\
(55.0)\end{array}$ & $\begin{array}{c}65 / 110 \\
(59.1)\end{array}$ & $\begin{array}{l}50 / 99 \\
(50.5)\end{array}$ & 0.213 \\
\hline $\begin{array}{c}\text { If a lecture or workshop related with online professional etiquette } \\
\text { (such as Facebook page, email, etc.) is available in a pharmacy } \\
\text { curriculum, do you think that this education will be helpful to keep } \\
\text { e-professionalism online in the future? }\end{array}$ & $\begin{array}{c}149 / 208 \\
(71.6)\end{array}$ & $\begin{array}{l}75 / 110 \\
(68.2)\end{array}$ & $\begin{array}{l}74 / 98 \\
(75.5)\end{array}$ & 0.242 \\
\hline
\end{tabular}

(Source: The questions were modified from reference 6 and 11)

* derived from chi-square test

Korea were considered in this study; thus, this difference may also occur.

Over $90 \%$ of students stated that pharmacy students should be accountable for their unethical or unprofessional behaviors on SNSs. This percentage is higher than those reported in other studies. ${ }^{6,11}$ Fifty-five percent of the first-year pharmacy students and $57 \%$ of graduating pharmacy students felt that students should be responsible for unprofessional behaviors found through SNSs. ${ }^{6,11}$ Some students in this study had also provided information on SNS that they did not want a faculty member (15.2\%) or a potential employer (12.1\%) to see. Compared with the results from other studies, ${ }^{6,11-12}$ the lower percentages of students gave positive responses to these questions. Additionally, $45 \%$ of students disagreed that a faculty member used an SNS for keeping a close relationship with them, whereas the higher percentages of students in other studies did not want a faculty member to use an SNS to "friend" them., ${ }^{6,11}$ Finally, the majority of students $(71.6 \%)$ indicated that providing a lecture or workshop regarding e-professionalism in pharmacy curricula would be helpful in order to maintain their professionalism online.

This study had a few limitations that should be mentioned. The survey was administered to pharmacy students at only one institution, making it difficult to generalize the results from this study to other institutions. Each question was also analyzed according to gender, but there were no significant differences between males and females in most questions. Consequently, various factors (e.g., age or grade) in the analysis should have been considered. In addition, the fourth-year students could not be included in the survey since they were on pharmacy practice experiences.

In future studies, similar surveys should be conducted in other institutions in order to compare this study with other studies and to evaluate overall patterns of SNS activities among Korean pharmacy students and their perceptions concerning e-professionalism. The educational sessions regarding harms from unprofessional behaviors online may be beneficial to enable pharmacy students to become well-prepared professionals before looking for pharmacy jobs. Thus, the studies assessing 
pharmacy students' views about e-professionalism before and after the sessions should be considered. In addition, one study reported that informing pharmacy students about a college's social media policy and making them cognizant of it positively affected their online behaviors concerning security and privacy. ${ }^{14}$ Most pharmacy schools in Korea have yet to establish polices regarding SNSs, so it is necessary that the schools create those polices and make pharmacy students aware of them. The term "e-professionalism" is relatively new and unfamiliar in Korea. Therefore, faculty members and administrators of pharmacy schools in Korea should introduce new issues related with "e-professionalism" to pharmacy students in classes or workshops and help them become aware of it before starting to seek employment as pharmacists.

\section{CONCLUSION}

This study is the first to provide insight into pharmacy students' SNS activities and their perceptions regarding e-professionalism under the newly implemented 6-year pharmacy educational system in South Korea. Many Korean pharmacy students had several SNS profiles including Kakaotalk. More than half of pharmacy students in this study felt that it is fair for potential pharmacy employers to use SNS information in making a hiring decision. A large percentage of students in this study also felt that pharmacy students should be held accountable for their unethical or unprofessional behaviors on SNSs.

\section{ACKNOWLEDGEMENT}

This study was supported by a research fund from Chosun University, 2015.

\section{CONFLICTS OF INTEREST}

There is no conflict of interest for the present communication.

\section{SUMMARY}

- A number of Korean pharmacy students in this study possessed several SNS profiles.

- A large percentage of Korean pharmacy students in the study responded that they should be responsible for their unethical or unprofessional behaviors on SNSs.

- Over $50 \%$ of Korean pharmacy students in the study responded that it is fair for future pharmacy employers to utilize SNS information in the hiring process.

- Faculty members and administrators of Korean pharmacy schools should address new issues regarding "e-professionalism" in classes or workshops.

\section{Pictorial Abstract}

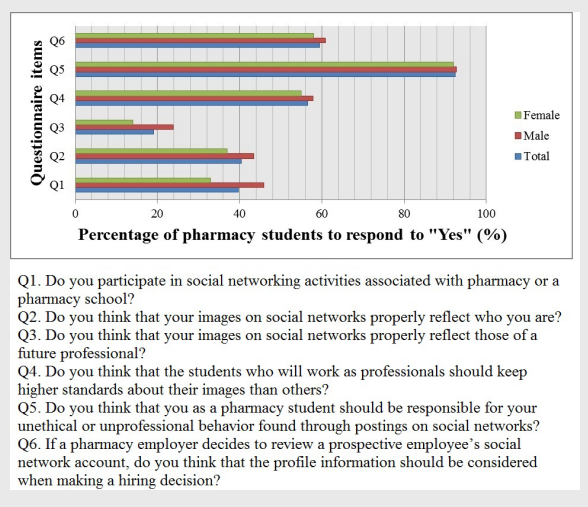

\section{About Authors}

Eun Joo Choi, is currently working as assistant professor at College of Pharmacy, Chosun University, South Korea. She obtained bachelor's degree in Pharmacy and Master of Science at Sungkyunkwan University, South Korea. She worked as clinical pharmacist in a tertiary teaching hospital and retail pharmacy for about 6 years. She also acquired Doctor of Pharmacy degree at Nova Southeastern University in the United States. Her research interests are in pharmaceutical education, clinical pharmacy and clinical pharmacology.

Young-Mo Yang, is a doctoral student at College of Pharmacy, Chosun University, Korea. He obtained Master of Science at the same university. He also graduated with Doctor of Pharmacy degree at Midwestern University in the United States. His doctoral research focuses on pharmacy education and clinical pharmacy. 


\section{ABBREVIATION USED}

\section{SNS : Social Networking Service.}

\section{REFERENCES}

1. Kwon O, Wen Y. An empirical study of the factors affecting social network service use. Computers in Human Behavior. 2010; 26(2): 254-63.

2. Boyd DM, Ellison NB. Social network sites: definition, history, and scholarship. Journal of Computer-Mediated Communication. 2008; 13(1): 210-30.

3. Cain J, Fink JL. Legal and ethical issues regarding social media and pharmacy education. Am J Pharm Educ. 2010; 74(10): 184.

4. Choi E. Kakaotalk, a mobile social platform pioneer. Available from http://www. seriworld.org/16/qt_Section_list.html? mncd=0303\&pub=20130119\&dep= 3\&pubseq=295\&year=2013. Accessed July 13, 2015.

5. Cain J. Online social networking issues within academia and pharmacy education. Am J Pharm Educ. 2008; 72(1): 10.

6. Cain J, Scott DR, Akers P. Pharmacy students' facebook activity and opinions regarding accountability and e-professionalism. Am J Pharm Educ. 2009; 73(6): 104.
7. Moeinzadeh A, Massoud T, Hajj ME. Facebook activity and views regarding e-professionalism: a survey of pharmacy students in Qatar. Presented in 2012 ACCP Annual Meeting. 2012.

8. Kaczmarczyk JM, Chuang A, Dugoff L, et al. e-Professionalism: a new frontier in medical education. Teach Learn Med. 2013; 25(2): 165-70.

9. Mattingly $\mathrm{TJ}$, Cain J, Fink JL. Pharmacists on facebook: online social networking and the profession. J Am Pharm Assoc. 2010; 50(3): 424-7.

10. MacDonald J, Sohn S, Ellis P. Privacy, professionalism and facebook: a dilemma for young doctors. Med Educ. 2010; 44(8): 805-13.

11. Ness GL, Sheehan AH, Snyder ME, et al. Graduating pharmacy students' perspectives on e-professionalism and social media. Am J Pharm Educ. 2013; 77(7): 146.

12. Hall M, Hanna LA, Huey G. Use and views on social networking sites of pharmacy students in the united kingdom. Am J Pharm Educ. 2013; 77(1): 9.

13. Kim E, Ghimire S. Career perspectives of future graduates of the newly implemented 6-year pharmacy educational system in South Korea. Am J Pharm Educ. 2013; 77(2): 37.

14. Williams J, Field C, James K. The effects of a social media policy on pharmacy students' facebook security settings. Am J Pharm Educ. 2011; 75(9): 177. 